\title{
Novel treatment for submucosal tumor of the duodenum: Non-exposed endoscopic wall-inversion surgery
}

\author{
Prasit Mahawongkajit* \\ Department of Surgery, Faculty of Medicine, Thammasat University, Pathumthani, Thailand
}

\begin{abstract}
Pancreatoduodenectomy is the standard approach for duodenal resection. Partial duodenal resection has also attempted as an alternative treatment option for tumors, which do not require lymph node dissection and to reduce morbidity risks of the standard procedure. Several studies reported laparoscopic and endoscopic cooperative surgery (LECS) for the localization of the duodenal lesion, its precise resection respecting oncologic principles and the closure of the defect. Non-Exposed Endoscopic Wall-inversion Surgery (NEWS) is the novel minimally invasive surgical technique for gastric SMTs has the accuracy advantage to determine the resection line with no risk of peritoneal contamination. LECS and NEWS are the effective strategy, a safe procedure, and one of the minimally invasive treatment options for gastric and anterior wall of $1^{\text {st }}$ part duodenal SMT that NEWS is sufficiently accurate to determine the resection margin and avoid peritoneal contamination.
\end{abstract}

\section{To the Editor}

The term submucosal tumor (SMT) or subepithelial tumor (SET) describes any protuberance in the gastrointestinal tract where the overlying mucosa is not involved. The distribution of SMTs in the upper digestive tract varied in many reports, with the stomach being the organ most frequently involved $[1,2]$. Pancreatoduodenectomy is the standard approach for duodenal resection. Partial duodenal resection has also attempted as an alternative treatment option for tumors, which do not require lymph node dissection and to reduce morbidity risks of the standard procedure $[3,4]$. Several studies reported laparoscopic and endoscopic cooperative surgery (LECS) techniques for the localization of the duodenal lesion, its precise resection respecting oncologic principles and the closure of the defect [5]. Recently, several studies have developed and described the endoscopic and laparoscopic approaches, which have the advantages of being a minimally invasive technique and having precision at the tumor resection margin. NEWS is a novel technique developed and published by Goto et al. [6] which demonstrates a minimally invasive procedure using laparoscopic surgery and endoscopic intervention with full-thickness resection of the gastric wall and avoids contamination risk (Figure 1). NEWS is the novel minimally invasive surgical technique for gastric SMTs and combined with sentinel node basin dissection for early gastric cancer has the accuracy advantage to determine the resection line with no risk of peritoneal contamination [6-9]. In our institute, we performed NEWS for gastric SMT less than $3 \mathrm{~cm}$ in diameter. We discussed with the patient the options available and selected NEWS for anterior small duodenal SMT that could be removed perorally. The precise free tumor margin of full-thickness resection was successful without any complication. Two technically challenging steps encountered in our procedure. In the first, the endoscope could not apply lateral and distal mucosal marking at the duodenal bulb. In the second, the step of the mucosal dissection after complete seromuscular suturing and inversion of the lesion, meticulous inspection via endoscopic view when performing the multiple serosal marking and careful dissection from the proximal to complete removal of the tumor was necessary because the endoscope operated in only a straightforward direction. The thin wall and narrowing lumen of the duodenum are the critical reasons why the technique could not apply

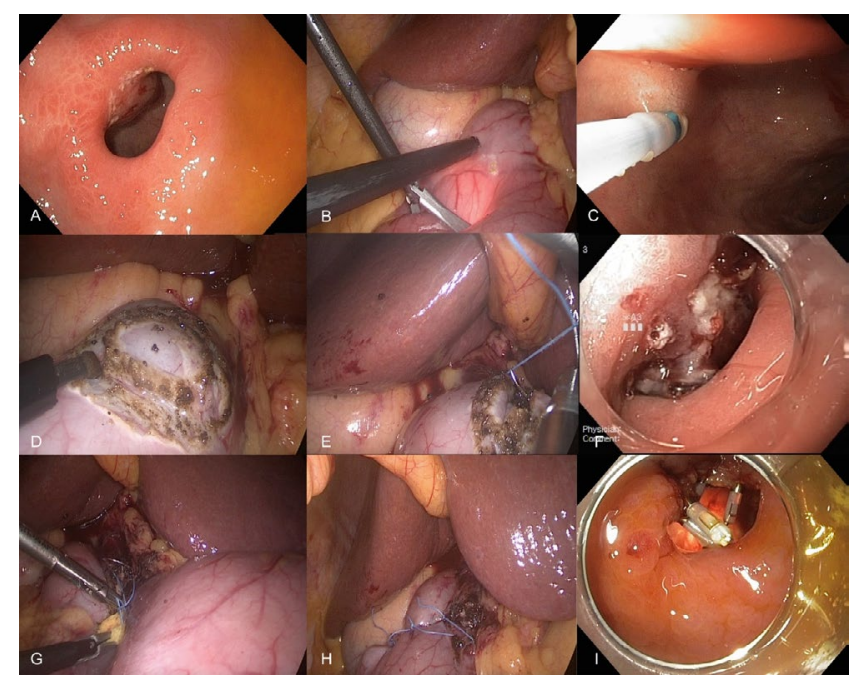

Figure 1. Procedures of Non-exposed Endoscopic Wall-inversion Surgery (NEWS). (A) The mucosal markings were performed using a Dual knife at proximal side of lesion. (B C) Laparoscopic seroral markings were guided by Dual knife pressing and carefully under image of endoscopic view especially on the lateral and distal side of lesion at duodenal wall. (D) The circumferential serosal incision followed the previous serosal markings. (E) The serosal incision was sutured. (F) The lesion was inverted protruding into the duodenal lumen. (G) During the suturing, a sponge was inserted between the serosal layer of the inverted lesion and the continuous serosal suture line. $(\mathrm{H})$ Simple interrupted sutures were applied to reinforce the seromuscular continuous suture. (I) The mucosal incision was closed with clips.

${ }^{\star}$ Correspondence to: Prasit Mahawongkajit, M.D, Ph.D, Department of Surgery, Faculty of Medicine, Thammasat University (Rangsit Campus), 99/209 Moo 18, Paholyothin Road, Amphur Klongluang, Pathumthani, Thailand, 12120; E-mail: prasit_md@yahoo.com

Key words: submucosal tumor, subepithelial tumor, non-exposed endoscopic wall-inversion surgery (NEWS), duodenum, laparoscopic endoscopic cooperative surgery (LECS)

Received: December 18, 2019; Accepted: December 30, 2019; Published: January 06, 2020 
endoscopy in retroflexion. The intraoperative and postoperative patient condition was stable [10].

LECS and NEWS are effective strategy, a safe procedure, and one of the minimally invasive treatment options for gastric and anterior wall of $1^{\text {st }}$ part duodenal SMT that NEWS is sufficiently accurate to determine the resection margin and avoid peritoneal contamination. Further studies are required to reassure that NEWS can be encouraged as the standard treatment for small gastric and duodenal tumors.

\section{Acknowledgments}

Special thanks to Norman Mangnall for assistance in editing the English version of this report.

Each author's contribution to the following criteria for authorship: conception and design; analysis and interpretation of the data; drafting of the article; critical revision of the article for important intellectual content; final approval of the article.

\section{References}

1. Kawamoto K, Yamada Y, Utsunomiya T, Okamura H, Mizuguchi M, et al. (1997) Gastrointestinal submucosal tumors: evaluation with endoscopic US. Radiology 205 733-740. [Crossref]

2. Polkowski M (2005) Endoscopic ultrasound and endoscopic ultrasound-guided fineneedle biopsy for the diagnosis of malignant submucosal tumors. Endoscopy 37: 635645. [Crossref]
3. Chok AY, Koh YX, Ow MY, Allen JC Jr, Goh BK (2014) A systematic review and metaanalysis comparing pancreaticoduodenectomy versus limited resection for duodenal gastrointestinal stromal tumors. Ann Surg Oncol 21: 3429-3438. [Crossref]

4. Chung JC, Kim HC, Hur SM (2016) Limited resections for duodenal gastrointestinal stromal tumors and their oncologic outcomes. Surg Today 46: 110-116. [Crossref]

5. Irino T, Nunobe S, Hiki N, Yamamoto Y, Hirasawa T, et al. (2015) Laparoscopicendoscopic cooperative surgery for duodenal tumors: a unique procedure that helps ensure the safety of endoscopic submucosal dissection. Endoscopy 47: 349-351. [Crossref]

6. Goto O, Mitsui T, Fujishiro M, Wada I, Shimizu N, et al. (2011) New method of endoscopic full-thickness resection: a pilot study of non-exposed endoscopic wall-inversion surgery in an ex vivo porcine model. Gastric Cancer 14: 183-187. [Crossref]

7. Goto O, Takeuchi H, Kawakubo H, Sasaki M, Matsuda T, et al. (2015) First case of non-exposed endoscopic wall-inversion surgery with sentinel node basin dissection for early gastric cancer. Gastric Cancer 18: 434-439. [Crossref]

8. Goto O, Takeuchi H, Sasaki M, Kawakubo H, Akimoto T, et al. (2016) Laparoscopyassisted endoscopic full-thickness resection of gastric subepithelial tumors using a nonexposure technique. Endoscopy 48: 1010-1015. [Crossref]

9. Mahawongkajit P, Techagumpuch A, Suthiwartnarueput W (2017) Non-exposed endoscopic wall-inversion surgery for a gastrointestinal stromal tumor of the stomach: A case report. Oncol Lett 14: 4746-4750. [Crossref]

10. Mahawongkajit P, Techagumpuch A, Chanswangphuvana P (2017) Non-exposed endoscopic wall-inversion surgery for submucosal tumor of the duodenum: Novel case report. Dig Endosc 29: 818-819. [Crossref]

Copyright: (C2019 Mahawongkajit P. This is an open-access article distributed under the terms of the Creative Commons Attribution License, which permits unrestricted use, distribution, and reproduction in any medium, provided the original author and source are credited. 